\title{
Impact of left atrial volume reduction concomitant with atrial fibrillation surgery on left atrial geometry and mechanical function
}

\author{
Akira Marui, MD, PhD, ${ }^{a}$ Yoshiaki Saji, MD, ${ }^{a}$ Takeshi Nishina, MD, PhD, ${ }^{a}$ Eiji Tadamura, MD, PhD, ${ }^{b}$ Shotaro Kanao, MD, ${ }^{b}$ \\ Takeshi Shimamoto, MD, ${ }^{a}$ Nozomu Sasahashi, MD, ${ }^{a}$ Tadashi Ikeda, MD, PhD, and Masashi Komeda, MD, PhD ${ }^{a}$
}

From the Department of Cardiovascular Surgery, ${ }^{\mathrm{a}}$ and Department of Diagnostic Imaging and Nuclear Medicine, ${ }^{\mathrm{b}}$ Graduate School of Medicine, Kyoto University, Kyoto, Japan.

Read at the Eighty-seventh Annual Meeting of The American Association for Thoracic Surgery, Washington, DC, May 5-9, 2007.

Received for publication May 31, 2007; revisions received Nov 27, 2007; accepted for publication Feb 25, 2008.

Address for reprints: Masashi Komeda, MD $\mathrm{PhD}$, Department of Cardiovascular Surgery, Graduate School of Medicine, Kyoto University, 54 Shogoin-Kawahara, Sakyo, Kyoto 606-8507, Japan (E-mail: komelab@ kuhp.kyoto-u.ac.jp).

J Thorac Cardiovasc Surg 2008;135:1297305

$0022-5223 / \$ 34.00$

Copyright $(\odot 2008$ by The American Association for Thoracic Surgery

doi:10.1016/j.jtcvs.2008.02.026
Objective: Left atrial geometry and mechanical functions exert a profound effect on left ventricular filling and overall cardiovascular performance. We sought to investigate the perioperative factors that influence left atrial geometry and mechanical functions after the Maze procedure in patients with refractory atrial fibrillation and left atrial enlargement.

Methods: Seventy-four patients with atrial fibrillation and left atrial enlargement (diameter $\geq 60 \mathrm{~mm}$ ) underwent the Maze procedure in association with mitral valve surgery. The maximum left atrial volume and left atrial mechanical functions (booster pump, reservoir, and conduit function [\%]) were calculated from the left atrial volume-cardiac cycle curves obtained by magnetic resonance imaging. A stepwise multiple regression analysis was performed to determine the independent variables that influenced the postoperative left atrial geometry and function.

Results: The multivariate analysis showed that left atrial reduction surgery concomitant with the Maze procedure and the postoperative maintenance of sinus rhythm were predominant independent variables for postoperative left atrial geometry and mechanical functions. Among the 58 patients who recovered sinus rhythm, the postoperative left atrial geometry and function were compared between patients with (VR group) and without (control group) left atrial volume reduction. At a mean follow-up period of 13.8 months, sinus rhythm recovery rate was better $(85 \%$ vs $68 \%, P<.05)$ in the VR group and maximum left atrial volume was less $(116 \pm 25 \mathrm{~mL}$ vs $287 \pm 73 \mathrm{~mL}, P<.001)$ than in the control group. The maximum left atrial volume reduced with time only in the VR group (reverse remodeling). Postoperative booster pump and reservoir function in the VR group were better than in the control group $(25 \% \pm 6 \%$ vs $11 \% \pm 4 \%$ and $34 \% \pm 7 \%$ vs $16 \% \pm 4 \%$, respectively, $P<.001$ ), whereas the conduit function in the VR group was lower than in the control group, indicating that the improvement of the booster pump and reservoir function compensated for the conduit function to left ventricular filling.

Conclusion: Left atrial reduction concomitant with the Maze procedure helped restore both contraction (booster pump) and compliance (reservoir) of the left atrium and facilitated left atrial reverse remolding. Left atrial volume reduction and postoperative maintenance of sinus rhythm may be desirable in patients with refractory AF and left atrial enlargement.

$\mathrm{L}$ eft atrial (LA) enlargement has been reported to be a predictor for recurrent atrial fibrillation (AF) after the Maze procedure. ${ }^{1-3}$ We and others have reported that LA volume reduction surgery concomitant with the Maze procedure facilitated sinus rhythm recovery even in patients with refractory AF and LA enlargement. ${ }^{4-7}$ However, little is known about the recovery of LA geometry and mechanical function after these procedures.

The left atrium serves 3 major roles—booster pump, reservoir, and conduit—that exert a profound effect on left ventricular (LV) filling and overall cardiovascular 

Abbreviations and Acronyms
$\mathrm{AF}=$ atrial fibrillation
$\mathrm{BPF}=$ booster pump function
$\mathrm{CF}=$ conduit function
$\mathrm{LA}=$ left atrial
$\mathrm{LV}=$ left ventricular
MRI = magnetic resonance imaging
$\mathrm{RF}=$ reservoir function

performance. ${ }^{8,9}$ We evaluated the LA booster pump function (BPF) early after LA reduction surgery concomitant with the Maze procedure using magnetic resonance imaging (MRI). ${ }^{10}$ We did not evaluate the reservoir and conduit function (CF). Several factors, such as mitral valve pathology (regurgitation or stenosis) and operations (repair or replacement), also influence postoperative LA geometry and mechanical function.

We sought to determine the independent variables that influence postoperative LA geometry and global mechanical function after mitral valve surgery in patients with refractory $\mathrm{AF}$ and LA enlargement. We investigated the influences of these factors on the restoration of LA geometry and mechanical functions.

\section{Patients and Methods \\ Study Population}

Between 2000 and 2006, 127 patients with chronic (permanent or persistent) AF underwent the Maze procedures associated with mitral valve surgery at Kyoto University. Among them, 83 patients had preoperative LA enlargement (LA dimension $\geq 60 \mathrm{~mm}$ ). LA diameter was measured by means of M-mode transthoracic echocardiography. Of the 83 patients, 7 with contraindications for MRI (eg, pre- or postoperative implantation of permanent pacemaker, implantable cardioverter defibrillator, or intracranial surgical clip) were excluded. Two urgent operations were also excluded because of a lack of preoperative MRI scans. Consequently, 74 patients were retrospectively analyzed (Table 1 ).

\section{Surgical Procedure}

In June of 2002, we began performing LA volume reduction surgery in association with the Maze procedure in patients with LA enlargement. Before June of 2002, 28 patients underwent the Maze procedure alone. After June of 2002, 46 patients underwent the Maze procedure concomitant with the LA reduction surgery that we developed. ${ }^{4}$ The Maze procedures were primarily based on the modified Cox-Maze III with cryoablation ${ }^{11}$ or the LA Maze procedure. ${ }^{12}$ The LA lesion set was similar in both procedures. The LA volume reduction technique without cut and sew was performed as previously described $^{4}$ (Figure 1). Briefly, via a standard right-sided left atriotomy, continuous horizontal-mattress suture was placed on the LA wall along the pulmonary vein isolation line. The suture was tightened so that the redundant left atrium was plicated. Confinement cryoablation was applied to the suture line so that the plicated left atrium was both anatomically and electrically isolated. Other cryoablation was applied as previously reported. ${ }^{4,11,12} \mathrm{We}$ used the cryoablation
TABLE 1. Preoperative data

\begin{tabular}{lc} 
Demographics & \\
Patients, $\mathrm{n}$ & 74 \\
Male sex, $\mathrm{n}(\%)$ & $32(43 \%)$ \\
Age (y) & $62 \pm 14$ \\
NYHA class & $2.7 \pm 1.0$ \\
Duration of AF (y) & $10 \pm 6$ \\
Type of AF & \\
$\quad$ Permanent, $\mathrm{n}(\%)$ & $56(76 \%)$ \\
$\quad$ Persistent, $\mathrm{n}(\%)$ & $18(24 \%)$ \\
Mitral valve cause & \\
$\quad$ Regurgitation, $\mathrm{n}(\%)$ & $47(64 \%)$ \\
$\quad$ Stenosis, $\mathrm{n}(\%)$ & $27(36 \%)$ \\
Preoperative MRI data & \\
Maximum LA volume (mL) & $361 \pm 74$ \\
Booster pump function (\%) & $\mathrm{N} / \mathrm{A}$ \\
Reservoir function (\%) & $13 \pm 5$ \\
Conduit function (\%) & $62 \pm 9$ \\
LVEF (\%) & $48 \pm 15$ \\
LVEDV (mL) & $131 \pm 34$ \\
\hline
\end{tabular}

$N Y H A$, New York Heart Association; $A F$, atrial fibrillation; $L A$, left atrium; $\angle V E F$, left ventricular ejection fraction; $\angle V E D V$, left ventricular end-diastolic dimension; $M R I$, magnetic resonance imaging; $N / A$, not applicable.

only for the ablation device. Mitral valve repair or prosthetic valve replacement was performed immediately before or after the VR technique. The same surgeon (M.K.) performed the operations in all patients in a homogenous fashion during the entire study period.

\section{Magnetic Resonance Imaging and Image Interpretation}

MRI was performed with a 1.5-T whole-body imager (Symphony; Siemens, Erlangen, Germany) with multiple surface coils connected to phased-array receivers. Breath-hold cine MRI was performed with the segmented steady-state free precession sequence. ${ }^{13}$ MRI scans were analyzed by an observer without any clinical information but with the aid of commercially available software (Argus, Siemens). ${ }^{14}$

Left atrial parameters. Axial slices over the entire LA cavity were used for the subsequent quantitative assessment. The left atrium was encompassed by $8-\mathrm{mm}$ slices with 2-mm interslice gaps. Each slice was obtained for 10 heart beats with an electrocardiographically prospectively gated fast low-angle shot cinematographic pulse sequence, with echocardiography sharing to improve the temporal resolution. ${ }^{15}$ The LA area (centimeters squared) of each slice was calculated from manually drawn endocardial boundaries of the LA cavity using ExaVision software (Ziosoft, Inc, Tokyo, Japan). LA volume was achieved using the slice summation method, which is based on the summation of the volume of each slice taking the slice thickness and interslice distance into account. ${ }^{16-18}$ LA volume-time curves were depicted by plotting each instantaneous LA volume against the time after the R-wave of electrocardiogram (Figure 2). ${ }^{16-19}$

The reservoir volume was calculated as the difference between volume B (maximum LA volume) and volume C (LA volume at the end of rapid emptying). ${ }^{16}$ The booster pump volume was calculated as the difference between volume D (LA volume before contraction) and volume A (minimum LA volume). The conduit 


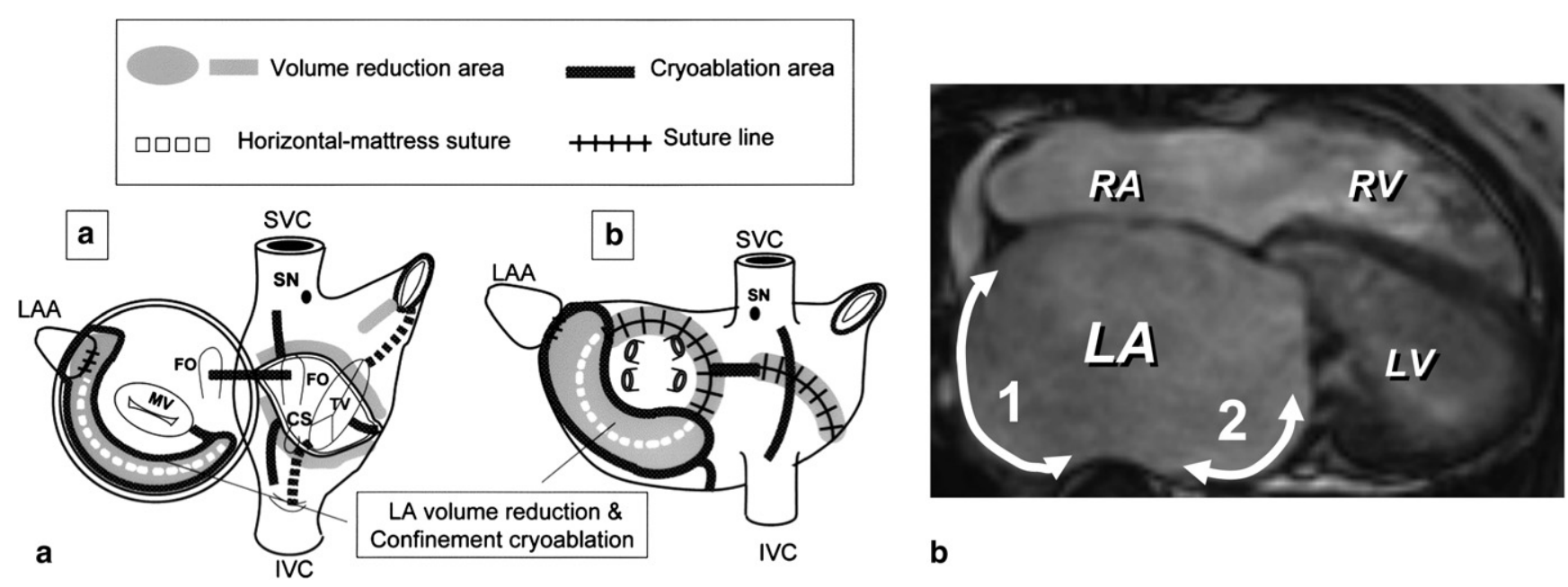

Figure 1. Maze procedure with LA volume reduction surgery. a, Schema of LA volume reduction surgery. The redundant LA wall between the mitral annulus and the left pulmonary veins was plicated with continuous horizontal mattress sutures (anatomic isolation). The plicated area was isolated by means of confinement cryoablation along the suture line (electrical isolation). b, MRI of LA plicated area. LA is plicated in areas 1 and 2. 1: Right lateral wall 2: Redundant LA wall between the mitral annulus and the left pulmonary veins. $L A A$, Left atrial appendage; $S V C$, superior vena cava; $I V C$, inferior vena cava; $F O$, foramen ovale; $S N$, sinus node; $C S$, coronary sinus; $M V$, mitral valve; $T V$, tricuspid valve; $L V$, left ventricle; $R A$, right atrium; $R V$, right ventricle.

volume was calculated by subtracting the booster pump and reservoir volumes from the LV stroke volume. In principle, the reservoir function $(\mathrm{RF})$ was calculated as the percentage of decrease from volume $\mathrm{B}$ to $\mathrm{C}$, and the BPF was calculated as the percentage of decrease from volume $\mathrm{D}$ to $\mathrm{A} .{ }^{16-19}$ The $\mathrm{CF}$ was defined as the ratio of conduit volume to LV stroke volume. For each patient, we modified the methodology reported by Jarvinen and colleagues. ${ }^{16}$ If there was an increase in booster pump volume in late diastole, the booster pump volume was calculated as noted above (Figure 2, $A$ ). If there was a plateau in the volume-time curve during late diastole, the booster pump volume was calculated as the volume decrease during the final $200 \mathrm{~ms}$ of the heart period (Figure 2, B). If the volume-time curve was continuously downsloping during diastole, the reservoir volume was taken to be the volume decrease before the final 200 ms of the heart period (Figure 2,C). The booster pump volume was then the volume reduction over the remaining cardiac cycle. MRI scans were obtained 3 to 5 times, and an average volume of each time point was used for analysis in patients with AF. In patients with sinus rhythm, an average of 3 MRI scans were used.

Left ventricular parameters. Cine MRI scans of 10 to 12 contiguous sections with $10-\mathrm{mm}$ section thickness were obtained in the short-axis plane, covering the entire LV from the base to the apex, to acquire 3-dimensional LV data. ${ }^{13,14}$

\section{Postoperative Management and Follow-up}

Postoperative management was performed as previously described. ${ }^{4}$ Patients were evaluated by MRI preoperatively, 1 month postoperatively, and during the follow-up.

\section{Statistical Analysis}

All values are expressed as the mean \pm standard deviation. Statistical analysis comparing the 2 groups were performed with the
Wilcoxon rank-sum test or the Fisher exact probability test for categoric variables. A stepwise multiple regression analysis was performed to assess the influence of the following independent variables on postoperative LA geometry and mechanical functions. Perioperative independent variables were age, sex, New York Heart Association class, duration of AF, type of AF (permanent or persistent), mitral valve pathology (regurgitation or stenosis), mitral valve surgery (repair or replacement), type of Maze operation (the modified Cox-Maze III or LA Maze), presence of LA reduction surgery, and concomitant procedures. Follow-up variables were LV ejection fraction, LV end-diastolic volume, and the maintenance of sinus rhythm. Variables were excluded from the regression analysis at each step of calculations if the $F$ value was less than 4.0. All statistical analyses were performed with StatView software (SAS Institute Inc, Cary, NC).

\section{Results}

\section{General Features}

Operative procedures are shown in Table 2. One patient died of a noncardiac event after discharge. There was no stroke or thromboembolism during the follow-up. At the last followup, 58 patients $(78 \%)$ recovered sinus rhythm.

\section{Stepwise Multiple Regression Analysis}

Table 3 shows the results of a stepwise multiple regression analysis to assess LA geometry and mechanical function during the follow-up. The postoperative maximum LA volume was negatively related to the concomitant LA reduction surgery $(\mathrm{F}=195.0)$ and maintenance of sinus rhythm $(\mathrm{F}=9.0)$, and positively related to the preoperative duration 


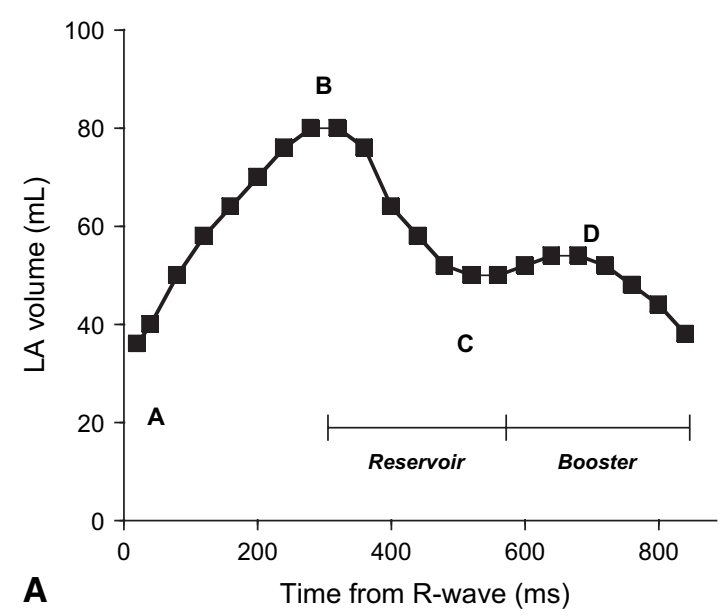

of $\mathrm{AF}(\mathrm{F}=13.3)$ and type of $\mathrm{AF}$ (permanent, $\mathrm{F}=5.5)$. The postoperative BPF was positively related to the concomitant LA reduction $(F=97.1)$ and negatively related to the preoperative duration of $\mathrm{AF}(\mathrm{F}=9.7)$. The postoperative $\mathrm{RF}$ was positively related to the concomitant LA reduction $(\mathrm{F}=131.4)$ and the maintenance of sinus rhythm $(\mathrm{F}=28.2)$, and negatively related to the preoperative duration of $\mathrm{AF}$ $(\mathrm{F}=6.0)$. The postoperative $\mathrm{CF}$ was negatively related to the maintenance of sinus rhythm $(\mathrm{F}=30.2)$ and concomitant LA reduction $(\mathrm{F}=23.0)$. These results suggest that the concomitant LA reduction and maintenance of sinus rhythm and preoperative duration of $\mathrm{AF}$ predominantly influenced the postoperative LA geometry and function.

\section{TABLE 2. Operative procedures}

\begin{tabular}{lc} 
Mitral valve surgery & \\
MVR, $\mathrm{n}(\%)$ & $27(36 \%)$ \\
MVP, $\mathrm{n}(\%)$ & $47(64 \%)$ \\
Maze procedures & $52(70 \%)$ \\
Modified Cox Maze III, $\mathrm{n}(\%)$ & $22(30 \%)$ \\
LA Maze, $\mathrm{n}(\%)$ & \\
LA volume reduction surgery & $46(62 \%)$ \\
Yes, $\mathrm{n}(\%)$ & \\
Concomitant procedures & $43(58 \%)$ \\
TAP, $\mathrm{n}(\%)$ & $13(18 \%)$ \\
AVR, $\mathrm{n}(\%)$ & $4(5 \%)$ \\
CABG, $\mathrm{n}(\%)$ & $7(9 \%)$ \\
Others, n (\%) & \\
\hline
\end{tabular}

$\overline{M V R}$, Mitral valve replacement; $M V P$, mitral valve plasty; $L A$, left atrium; $T A P$, tricuspid annuloplasty; $A V R$, aortic valve replacement; $C A B G$, coronary artery bypass grafting.
Influence of Left Atrial Reduction on Postoperative Left Atrial Geometry and Function

On the basis of the results of the multivariate analysis, we assessed the influence of LA reduction on the restoration of LA geometry and mechanical function during the followup. To assess the influence of LA reduction more specifically, and because the BPF can be calculated only in patients with sinus rhythm, we assessed the postoperative LA geometry and mechanical function in patients who maintained sinus rhythm. Among the 58 patients who maintained sinus rhythm during the follow-up, 39 had undergone LA volume reduction (VR group) and 19 had not undergone LA reduction (control group). Sinus rhythm recovery rate was significantly better in the VR group $(85 \%$ vs $68 \%, P<.05)$.

The VR group had a longer preoperative duration of AF than the control group $(13 \pm 7$ years vs $9 \pm 4$ years, $P<.01)$. The follow-up period of MRI was $14.8 \pm 6.3$ months in the VR group and 11.9 \pm 4.6 months in the control group (total $13.8 \pm 5.9$ months). The follow-up periods were not different between the groups.

Left atrial geometry. The maximum LA volume in the VR group (Figure 3, open circle) was reduced at 1 month postoperatively compared with the preoperative volume $(157 \pm 35 \mathrm{~mL}$ vs $354 \pm 89 \mathrm{~mL}, P<.001)$. The maximum LA volume in the control group (square) was reduced at 1 month postoperatively, but not significantly $(312 \pm 86 \mathrm{~mL}$ vs $275 \pm 70 \mathrm{~mL}$ ), despite successful sinus rhythm recovery. The maximum LA volume in the VR group was significantly reduced during the follow-up period (reverse remodeling). There was no LA reverse remodeling during the follow-up in the control group. Figure 4 shows the representative 
TABLE 3. Significant independent variables that influenced the postoperative left atrium geometry and mechanical function (a stepwise multiple regression analysis)

\begin{tabular}{|c|c|c|c|c|c|c|c|c|}
\hline \multirow{3}{*}{$\begin{array}{c}\text { Postoperative LA } \\
\text { parameters }\end{array}$} & \multicolumn{8}{|c|}{ Significant variables } \\
\hline & \multicolumn{2}{|c|}{ LA reduction } & \multicolumn{2}{|c|}{ SR (postoperative maintenance) } & \multicolumn{2}{|c|}{ AF (preoperative duration) } & \multicolumn{2}{|c|}{ AF type (persistent or permanent) } \\
\hline & $\beta$ & $\mathbf{F}$ & $\beta$ & $\mathbf{F}$ & $\beta$ & $\mathbf{F}$ & $\beta$ & $\mathbf{F}$ \\
\hline Maximum volume & -0.82 & 195.0 & -0.18 & 9.0 & 0.22 & 13.3 & 0.14 & 5.5 \\
\hline Booster pump & 0.80 & 97.1 & \multicolumn{2}{|c|}{${ }^{\mathrm{a}} \mathrm{N} / \mathrm{A}$} & -0.25 & 9.7 & \multicolumn{2}{|c|}{$\mathrm{N} / \mathrm{S}$} \\
\hline Reservoir & 0.74 & 131.4 & 0.35 & 28.2 & -0.16 & 6.0 & \multicolumn{2}{|c|}{$\mathrm{N} / \mathrm{S}$} \\
\hline Conduit & -0.42 & 23.0 & -0.48 & 30.2 & \multicolumn{2}{|c|}{$\mathrm{N} / \mathrm{S}$} & \multicolumn{2}{|c|}{$\mathrm{N} / \mathrm{S}$} \\
\hline
\end{tabular}

$L A$, Left atrium; $S R$, sinus rhythm; $A F$, atrial fibrillation; $N / A$, not applicable; $N / S$, not significant. $\beta$, standard regression coefficient. $F>4.0$ were significant independent variables. ${ }^{a}$ Booster pump function can be calculated in patients with sinus rhythm.

MRI scans of the LA volume reduction surgery. A preoperative giant left atrium was reduced by LA volume reduction surgery, and the reduction was maintained 1 year after the operation.

Left atrial mechanical function. The BPF was better in the VR group than in the control group both at 1 month and at follow-up $(18 \% \pm 3 \%$ vs $10 \% \pm 3 \%$ and $25 \% \pm 6 \%$ vs $11 \% \pm 4 \%$, respectively, $P<.001$ ) (Figure 3 ). The BPF further improved during the follow-up period $(P<.05)$. One month postoperatively, the RF was better in the VR group than in the control group $(28 \% \pm 6 \%$ vs $17 \% \pm 3 \%$, $P<.001)$. In addition, the RF further improved during the follow-up period in the VR group (from $28 \% \pm 6 \%$ to $34 \%$ $\pm 7 \%, P<.05)$. The RF in the control group did not improve despite successful sinus rhythm recovery. The preoperative $\mathrm{CF}$ was not different between the groups. However, the $\mathrm{CF}$
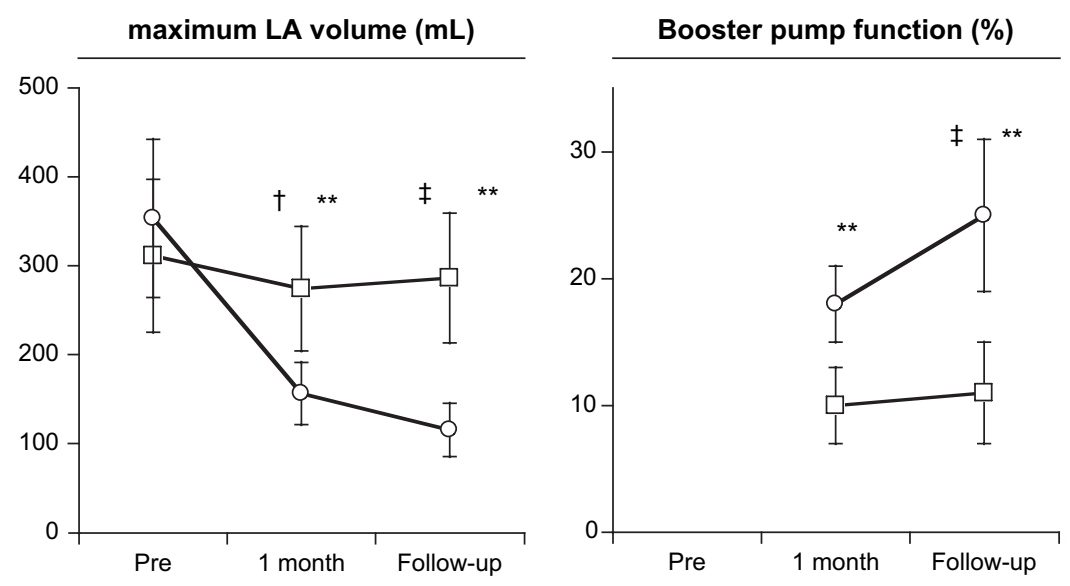

Figure 3. Restoration of LA geometry and mechanical functions in patients with postoperative maintenance of sinus rhythm. VR: Patients with LA volume reduction. Control: Patients without LA volume reduction. Pre, preoperation. 1 month: 1 month after the operation. Mean follow-up period was 13.8 months. ${ }^{*} P<.01 .{ }^{* *} P<.001$ vs control. ${ }^{\dagger} P<.01$ vs preoperation. ${ }^{\ddagger} P<.05$ vs 1 month.
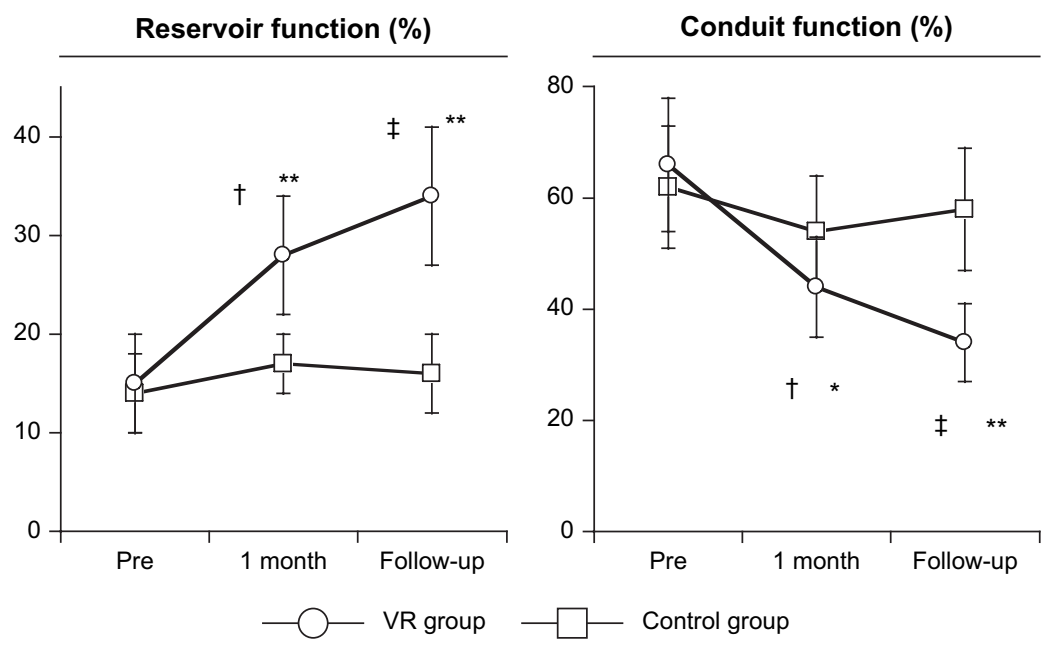

The Journal of Thoracic and Cardiovascular Surgery • Volume 135, Number 61301 


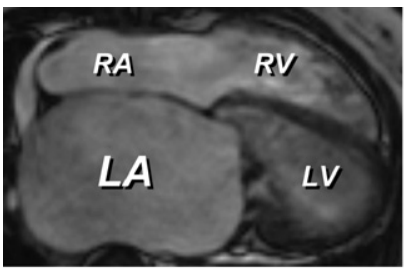

Preoperation

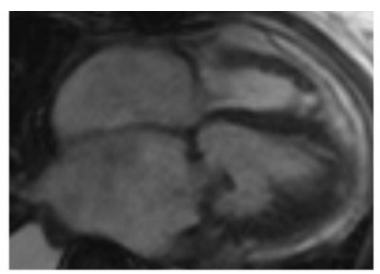

1 month

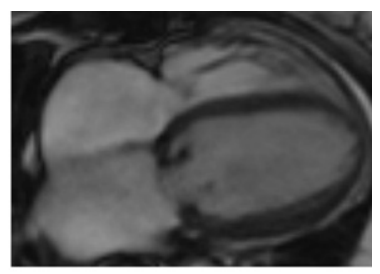

12 months
Figure 4. Representative magnetic resonance imaging scans of LA volume reduction surgery (at LA end systole). Preoperative giant left atrium was reduced by LA volume reduction surgery, and the reduction was maintained 1 year after the operation. 1 month: 1 month after the operation. 12 months: 12 months after the operation. $L A$, Left atrium; $L V$, left ventricle; $R A$, right atrium; $R V$, right ventricle. in the VR group was significantly lower than those in the control group both at 1 month and at follow-up (54\% $\pm 10 \%$ vs $44 \% \pm 9 \%, P<.05$ and $58 \% \pm 11 \%$ vs $34 \% \pm 7 \%$, respectively, $P<.001)$.

\section{Discussion}

\section{Key Findings}

We investigated the perioperative independent variables that influenced the postoperative LA geometry and global mechanical function in patients with AF and LA enlargement associated with mitral valve disease. A stepwise multiple regression analysis showed that LA reduction surgery concomitant with the Maze procedure predominantly influenced LA geometry and mechanical function during the follow-up. The Maze procedures without LA reduction did not improve the LA geometry or restore the BPF and RF, even when the Maze procedures successfully recovered the sinus rhythm. The Maze procedure concomitant with LA volume reduction surgery not only facilitated sinus rhythm recovery but also improved the LA geometry and promoted LA reverse remodeling during the 1-year follow-up. LA reduction improved $\mathrm{BPF}$ and $\mathrm{RF}$, and reduced $\mathrm{CF}$, which indicates that BPF and RF may have compensated for the $\mathrm{CF}$ in regard to $\mathrm{LV}$ filling. To our knowledge, this is the first study to show the efficacy of LA reduction on the restoration of the LA geometry and global mechanical function in patients with refractory AF and LA enlargement.

\section{Mechanical Function of the Left Atrium}

In the present study, we focused on 3 important LA mechanical functions. ${ }^{8,9}$ First, the left atrium is a "contractile chamber" that actively empties immediately before the onset of LV systole and establishes final LV end-diastolic volume. The BPF normally serves to augment the LV stroke volume by approximately $20 \% .^{8}$ Second, the left atrium is a "reservoir" that stores pulmonary venous return during LV contraction and isovolumic relaxation after the closure and before the opening of the mitral valve. The RF depends on LA compliance and plays an important role in early LA filling. Third, the left atrium is a "conduit" that empties its contents into the LV down a pressure gradient after the mitral valve opens and continues to passively transfer pulmonary venous blood flow during LV diastasis. The contraction, reservoir, and CFs of the LA mechanically facilitate the transition between the almost continuous flow through the pulmonary venous circulation and the intermittent filling of the LV.

\section{Post-ablation Left Atrial Booster Pump Function}

Several studies have evaluated the post-ablation (catheter or Maze) atrial function; however, most of these studies focused only on the BPF (contraction) of the left atrium. In echocardiographic evaluations, the Maze procedure or catheter ablation restored the postoperative LA contraction. ${ }^{12,20-22}$ Lemola and colleagues $^{23}$ and Verma and colleagues ${ }^{24}$ evaluated the post-ablation LA contraction by means of multi-detector computerized tomography. They showed that catheter ablation can restore the LA contraction in patients with chronic AF. MRI has been used to evaluate LA geometry and function in several studies; $;^{3,10,15-19,25,26}$ however, only a few studies have used MRI to evaluate post-Maze LA function. ${ }^{3,10}$

\section{Impact of Left Atrial Reduction on Postoperative Global Mechanical Function}

Some reports have shown the efficacy of LA reduction surgery concomitant with Maze procedures; however, all of these studies focused only on the techniques of the LA volume reduction by itself or the contributions of the techniques to sinus rhythm restoration. ${ }^{5-7}$ None of them evaluated postoperative LA function, and LA geometry was evaluated only by the M-mode echocardiography. Furthermore, they did not use a control (ie, non-LA reduction) group. Because of the limitations of these studies, their conclusion (ie, LA volume reduction surgery is effective to improve sinus rhythm recovery rate) may be faulty. We showed that the Maze procedure concomitant with LA reduction predominantly improved the $\mathrm{BPF}$ and RF, whereas the Maze procedure without LA reduction did not improve the geometry and functions even with the recovery of sinus rhythm. We speculate that the LA wall stress was decreased by LA reduction according to Laplace's law, and that LA reduction might increase LA compliance and contraction.

LV filling depends on active (BPF) and passive (RF and $\mathrm{CF}$ ) emptying of the left atrium. In contrast with the BPF and the RF, the CF in the VR group was lower than that in 
the control group. These results indicate that the improved $\mathrm{BPF}$ and RF largely contributed to the LV filling and relatively reduced the contribution of the $\mathrm{CF}$ to the $\mathrm{LV}$ filling in patients with LA reduction. Thus, LA reduction improves both active and passive emptying of the left atrium and positively contributes to LV filling.

\section{Postoperative Left Atrial Reverse Remodeling}

Reverse atrial remodeling (decrease in LA size) after the restoration of sinus rhythm is an important determinant for the postoperative reduction in LA size, and the reverse remodeling occurred after the successful Maze or RF ablation for $\mathrm{AF}^{4,7,15,22,24,27-29}$ Maintenance of sinus rhythm further reduced LA volume during the follow-up; however, in patients with AF recurrence, an additional increase in LA volume was observed. ${ }^{15,22}$ In the present study, patients who did not undergo LA volume reduction surgery did not have reduced LA volume despite successful sinus rhythm recovery, most likely because prolonged atrial overload before the surgery may have caused irreversible structural damage to the LA myocardium, or because the higher wall stress of the enlarged left atrium compared with the reduced left atrium might prevent the reverse remodeling.

\section{Clinical Relevance}

The recovery of LA global mechanical function can augment LV filling and LV stroke volume. The relative contribution of LA functions becomes more dominant in the setting of highrisk patients with LV dysfunction. ${ }^{8}$ In addition, LA volume reduction may contribute to the prevention of stroke or thromboembolism by increasing the blood flow velocity in the left atrium. These contributions may improve the morbidity and mortality of high-risk patients both early and late after the surgery.

\section{Study Limitations}

There are several limitations to the present study. First, this study was not a prospective randomized study; the operation was not randomly assigned for the VR group or control group. In addition, the follow-up period was approximately only 1 year. Further evaluation with a larger number of patients with long-term follow-up will be necessary. Second, gating the irregular rhythm with MRI scans was an important limitation. To minimize the irregularity, we used the same methodology that Therkelsen and associates used, ${ }^{15,30}$ who showed that MRI inherently compensates for an irregular heart rhythm when each image slice is acquired for 15 heart beats. They also demonstrated that atrial and ventricular imaging with MRI of the left- and right-sided chambers in AF is an accurate and highly reproducible method with the same level of variability as in patients with sinus rhythm. ${ }^{30}$ However, another method to compensate irregularity may be necessary. Third, we did not evaluate LV diastolic function. Because LV diastolic function has an influence on passive
LA emptying, it should have been included in the multivariate analysis. Fourth, we did not evaluate the loading condition preoperatively and postoperatively. Although we confirmed that patients did not show obvious volume overload by means of physical examinations, chest x-ray, and echocardiography, the loading condition may influence LA dimension and function.

\section{Conclusions}

LA reduction surgery not only facilitated sinus rhythm recovery but also helped restore LA mechanical functions and facilitated LA reverse remolding even in patients with long-standing $\mathrm{AF}$ and LA enlargement. LA reduction and maintenance of sinus rhythm may be desirable for patients with refractory AF who are not well suited for the Maze procedures, particularly in patients with LA enlargement. Further study with a larger number of patients and longer follow-up period, especially in a prospective and randomized fashion, is warranted.

\section{References}

1. Gaynor SL, Schuessler RB, Bailey MS, Ishii Y, Boineau JP, Gleva MJ, et al. Surgical treatment of atrial fibrillation: predictors of late recurrence. J Thorac Cardiovasc Surg. 2005;129:104-11.

2. Gillinov AM, Sirak J, Blackstone EH, McCarthy PM, Rajeswaran J, Pettersson G, et al. The Cox Maze procedure in mitral valve disease: predictors of recurrent atrial fibrillation. J Thorac Cardiovasc Surg. 2005; 130:1653-60.

3. Damiano RJ Jr, Schuessler RB, Voeller RK. Surgical treatment of atrial fibrillation: a look into the future. Semin Thorac Cardiovasc Surg. 2007; 19:39-45.

4. Marui A, Nishina T, Tambara K, Saji Y, Shimamoto T, Nishioka M, et al. A novel atrial volume reduction technique to enhance the Cox Maze procedure: initial results. J Thorac Cardiovasc Surg. 2006;132: 1047-53.

5. Winlaw DS, Farnsworth AE, Macdonald PS, Mundy JA, Spratt PM. Left atrial reduction: the forgotten Batista. Lancet. 1998;351:879-80.

6. Romano MA, Bach DS, Pagani FD, Prager RL, Deeb GM, Bolling SF. Atrial reduction plasty Cox Maze procedure: extended indications for atrial fibrillation surgery. Ann Thorac Surg. 2004;77:1282-7.

7. Badhwar V, Rovin JD, Davenport G, Pruitt JC, Lazzara RR, Ebra G, et al. Left atrial reduction enhances outcomes of modified Maze procedure for permanent atrial fibrillation during concomitant mitral surgery. Ann Thorac Surg. 2006;82:1758-63.

8. Abhayaratna WP, Seward JB, Appleton CP, Douglas PS, Oh JK, Tajik AJ, et al. Left atrial size: physiologic determinants and clinical applications. J Am Coll Cardiol. 2006;47:2357-63.

9. Pagel PS, Kehl F, Gare M, Hettrick DA, Kersten JR, Warltier DC. Mechanical function of the left atrium: new insights based on analysis of pressure-volume relations and Doppler echocardiography. Anesthesiology. 2003;98:975-94.

10. Marui A, Tambara K, Tadamura E, Saji Y, Sasahashi N, Ikeda T, et al. A novel approach to restore atrial function after the Maze procedure in patients with an enlarged left atrium. Eur J Cardiothorac Surg. 2007; 32:308-12. Epub 2007 Jun 18.

11. Nakajima H, Kobayashi J, Bando K, Niwaya K, Tagusari O, Sasako Y, et al. The effect of cryo-Maze procedure on early and intermediate term outcome in mitral valve disease: case matched study. Circulation. 2002; 106(Suppl I):I46-50.

12. Imai K, Sueda T, Orihashi K, Watari M, Matsuura Y. Clinical analysis of results of a simple left atrial procedure for chronic atrial fibrillation. Ann Thorac Surg. 2001;71:577-81.

13. Yamamuro M, Tadamura E, Kubo S, Toyoda H, Nishina T, Ohba M, et al. Cardiac functional analysis with multi-detector row CT and 
segmental reconstruction algorithm: comparison with echocardiography, SPECT, and MR imaging. Radiology. 2005;234:381-90.

14. Tadamura E, Kudoh T, Motooka M, Inubushi M, Shirakawa S, Hattori N, et al. Assessment of regional and global left ventricular function by reinjection T1-201 and rest Tc-99m sestamibi ECG-gated SPECT: comparison with three-dimensional magnetic resonance imaging. J Am Coll Cardiol. 1999;33:991-7.

15. Therkelsen SK, Groenning BA, Svendsen JH, Jensen GB. Atrial and ventricular volume and function evaluated by magnetic resonance imaging in patients with persistent atrial fibrillation before and after cardioversion. Am J Cardiol. 2006;97:1213-9.

16. Jarvinen VM, Kupari MM, Poutanen VP, Hekali PE. A simplified method for the determination of left atrial size and function using cine magnetic resonance imaging. Magn Reson Imaging. 1996;14:215-26.

17. Tseng WY, Liao TY, Wang JL. Normal systolic and diastolic functions of the left ventricle and left atrium by cine magnetic resonance imaging. J Cardiovasc Magn Reson. 2002;4:443-57.

18. Poutanen T, Ikonen A, Vainio P, Jokinen E, Tikanoja T. Left atrial volume assessed by transthoracic three dimensional echocardiography and magnetic resonance imaging: dynamic changes during the heart cycle in children. Heart. 2000;83:537-42.

19. Bowman AW, Kovacs SJ. Left atrial conduit volume is generated by deviation from the constant-volume state of the left heart: a combined MRI-echocardiographic study. Am J Physiol Heart Circ Physiol. 2004;286:H2416-24.

20. Feinberg MS, Waggoner AD, Kater KM, Cox JL, Lindsay BD, Perez JE. Restoration of atrial function after the Maze procedure for patients with atrial fibrillation. Assessment by Doppler echocardiography. Circulation. 1994;90(Part 2):II-285-92.

21. Cox JL, Ad N, Palazzo T, Fitzpatrick S, Suyderhoud JP, DeGroot KW, et al. Current status of the Maze procedure for the treatment of atrial fibrillation. Semin Thorac Cardiovasc Surg. 2000;12:15-9.

22. Fayad G, Le Tourneau T, Modine T, Azzaoui R, Ennezat PV, Decoene $\mathrm{C}$, et al. Endocardial radiofrequency ablation during mitral valve surgery: effect on cardiac rhythm, atrial size, and function. Ann Thorac Surg. 2005;79:1505-11.

23. Lemola K, Desjardins B, Sneider M, Case I, Chugh A, Good E, et al. Effect of left atrial circumferential ablation for atrial fibrillation on left atrial transport function. Heart Rhythm. 2005;2:923-8.

24. Verma A, Kilicaslan F, Adams JR, Hao S, Beheiry S, Minor S, et al. Extensive ablation during pulmonary vein antrum isolation has no adverse impact on left atrial function: an echocardiography and cine computed tomography analysis. J Cardiovasc Electrophysiol. 2006;17:741-6.

25. Westenberg JJ, van der Geest RJ, Lamb HJ, Versteegh MI, Braun J, Doornbos J, et al. MRI to evaluate left atrial and ventricular reverse remodeling after restrictive mitral annuloplasty in dilated cardiomyopathy. Circulation. 2005;112(Suppl):I437-42.

26. Rodevand O, Bjornerheim R, Ljosland M, Maehle J, Smith HJ, Ihlen H. Left atrial volumes assessed by three- and two-dimensional echocardiography compared to MRI estimates. Int J Card Imaging. 1999;15:397-410.

27. Thomas L, Boyd A, Thomas SP, Schiller NB, Ross DL. Atrial structural remodelling and restoration of atrial contraction after linear ablation for atrial fibrillation. Eur Heart J. 2003;24:1942-51.

28. Tops LF, Bax JJ, Zeppenfeld K, Jongbloed MR, van der Wall EE, Schalij MJ. Effect of radiofrequency catheter ablation for atrial fibrillation on left atrial cavity size. Am J Cardiol. 2006;97:1220-2.

29. Jessurun ER, van Hemel NM, Kelder JC, Defauw JAMT, de la Rivière AB, Ernst JMPG, et al. The effect of Maze operations on atrial volume. Ann Thorac Surg. 2003;75:51-6.

30. Therkelsen SK, Groenning BA, Svendsen JH, Jensen GB. Atrial and ventricular volume and function in persistent and permanent atrial fibrillation, a magnetic resonance imaging study. J Cardiovasc Magn Reson. 2005;7:465-73.

\section{Discussion}

Dr Ralph Damiano (St Louis, Mo). The effect of surgical procedures for AF on LA function remains poorly defined and controversial. Your group has used sophisticated imaging to begin to look at this important issue. We have also been interested in the functional changes in the left atrium after surgical ablation and have used similar technology, both clinically and experimentally, to help us address these important questions.

It can be hard to get these patients to return for follow-up, and I commend you on your persistence in what is a large series of followup MRI scans.

All of your patients were in permanent or persistent AF preoperatively. We have had tremendous problems obtaining MRI scans in these patients because of the difficulty in gating the irregular rhythm. How did you overcome these challenges and are you sure you did not miss part of the cardiac cycle in these patients?

Dr Marui. "Thank you, Dr. Damiano, for your kind comments and questions. We recognize your contribution to this field of $\mathrm{AF}$ surgery" Your first question is an important one, because gating of MRI in patients with AF is difficult. We used 3 to 5 cardiac-cycle series to evaluate the patients with $\mathrm{AF}$ for MRI evaluation. If patients recovered sinus rhythm, we used 3 cardiac-cycle series and averaged these data, and used them in the present study.

Dr Damiano. In your analysis you have omitted an important component of atrial emptying. The CF of the atrium is extremely important. By this I mean there is a certain percentage of blood flow of the LA volume that goes directly from the pulmonary veins through the mitral valve into the left ventricle that cannot be measured by your MRI atrial volumes. This can be calculated, though, by subtracting the reservoir and booster pump volume from the LV stroke volume, which you can obtain. In 20 healthy human volunteers we found that the conduit volume or the CF makes up approximately $40 \%$ of the LA contribution to LV filling. So you haven't told us about approximately $40 \%$ of LA emptying. Moreover, the ratio between the reservoir and the conduit volume is an important indicator of ventricular function, which is another confounder in this study. What were the differences in the CF of the left atrium in these patients? How may have it affected these results by just presenting booster pump and reservoir volumes?

Dr Marui. "That is a very excellent question." As Dr Damiano points out, we used only 2 functions: BPF and RF. The last one is $\mathrm{CF}$, and this is an important contribution to LA function. However, when we performed this study, we didn't know how to evaluate CF by MRI. Therefore we studied only BPF and RF. We recognize that Dr Damiano's institution (Department of Surgery, Barnes-Jewish Hospital, Washington University School of Medicine) has evaluated LA function, including CF by MRI, and are now obtaining more data, and we would like you to teach us how to evaluate CF.

Dr Damiano. It is excellent work, but it is still something to remember when you are looking at atrial dynamics. Postoperative ventricular systolic function, particularly diastolic relaxation, has a tremendous impact on LA function. I would say that in your control group, $43 \%$ of patients had mitral valve replacement versus only $33 \%$ in the volume reduction group. There was a similar discordance in the number of repairs. This may have had an impact on the postoperative ventricular function between the groups. Moreover, the types of concomitant surgeries varied in the 2 groups, as you acknowledged in your study limitations. Did you make any attempt to try to control for postoperative differences in ventricular function and how they may have affected your results? How can we be assured that the differences in atrial emptying that you have shown in this study aren't really a reflection of differences 
in ventricular function between the 2 groups unrelated to the arrhythmia operation but more related to their mitral valve surgery?

Dr Marui. As Dr Damiano points out, this is a major limitation of the study. We used 2 types of mitral valve surgery, and this may affect the results of the LA compliance, RF, and BPF. We must do a prospective randomized study for the evaluation of LA function including several postoperative parameters in the future.

Dr Takashi Nitta (Tokyo, Japan). I have a question about the mechanism of the improvement of the LA function. Everybody can understand that atrial systolic function can be increased and improved by volume reduction. It is like a Batista operation; reduced volume results in better contraction. I still have a problem understanding why the RF improved at the same time, because RF and systolic function are supplemented by each other. If the patient has sufficient systolic function, the patient no longer needs RF, and if the patient has sufficient RF, the patient no longer needs the atrial kick. So can you explain why the RF also improved even when the atrial systolic function had already improved?

Dr Marui. "Thank you. A very good question but a difficult question to answer." Before this study, we speculated that BPF would improve, but as you pointed out, the RF did not improve. The results were as shown here. The reasons are unclear. As you say, the improvement of LA RF in the present study might not mean recovery of atrial compliance alone. However, the mechanism of LA functional recovery after the LA volume reduction surgery is not fully understood; therefore, the reason for the improvement of LA compliance should be addressed in future studies. 